\title{
Criando falsas memórias em adultos por meio de imagens faciais
}

\author{
Verônica Souza Caixeta ${ }^{1}$ \\ Danilo Assis Pereira ${ }^{2}$
}

\begin{abstract}
RESUMO - O presente estudo baseia-se em verificar se é possível criar falsas memórias em adultos de ambos os sexos por meio de imagens faciais. Para tanto, realizou-se pesquisa com funcionários de uma empresa de transporte coletivo em Brasília. O método consistiu em apresentar imagens faciais na tela do computador fazendo com que acreditassem ter visualizado uma face que, na verdade, não foi apresentada entre as outras. Na parte introdutória, apresentam-se aspectos gerais e específicos da memória, entre eles, os tipos, estágios e distúrbios. Foram comparados os dados obtidos de homens e mulheres e por meio de tabelas, gráficos e com base em teorias de Fisiologia, os resultados encontrados para tal amostra de sujeitos permitiram chegar a conclusões.
\end{abstract}

Palavras-chave: memória, falsas memórias, imagens faciais, sugestão.

\section{Creating false memories in adults using facial images}

\begin{abstract}
The aim of this paper is the possibility in creating false memory in male and female adults using facial images. Thirty participants were recruited. The method consisted in presentating facial images in a computer screen and persuading them to believe that they have seen a face that, in fact, was not shown among the others. The research concluded that participants with low education level were more susceptible than the high education level ones.
\end{abstract}

Key words: memory, false memory, facial images, suggestion.

Este artigo foi baseado na monografia de final de curso de Psicologia do UniCEUB apresentada pela primeira autora e orientada pelo segundo autor.

${ }^{1}$ Psicóloga pelo UniCEUB.

${ }^{2}$ Pesquisador, Orientador e Professor de Psicologia do UniCEUB. 
O estudo da memória trata de extraordinário ponto de convergência de muitas decisões: localizá-la ou não; conservar apenas a vertente consciente da lembrança ou buscar conhecer o inconsciente; compreender o porquê e o como da aquisição e da lembrança; saber como se constrói na mente das pessoas por meio da sugestão, entre outros. Foi a multiplicidade de questões que me pareceu justificar os aspectos dos mecanismos da memória neste trabalho.

Seja como for, compreende-se bem que memória é um conjunto de sistemas de armazenamento diferentes uns dos outros e que alguns desses sistemas são acessíveis à consciência. A partir daí, de acordo com Davidoff (2001, p.205): "Os psicólogos usam a palavra memória para se referir aos variados processos e estruturas envolvidos no armazenamento e recuperação de experiências".

Acredita-se, desde Ramón y Cajal (1893), que as memórias consistiam na modificação da forma e, portanto, da função das sinapses que intervieram na formação dessas memórias. A maioria das informações que constituem memórias é aprendida por meio dos sentidos em episódios que são denominados experiências.

Falsas memórias são construídas combinando-se recordações verdadeiras com o conteúdo das sugestões recebidas de outros. Durante o processo, os indivíduos podem esquecer a fonte da informação. Este é um exemplo clássico de confusão sobre a origem da informação na qual o conteúdo e a proveniência da informação estão dissociados ${ }^{1}$. A presente pesquisa pretende mostrar se é possível criar falsas memórias em adultos por meio de imagens faciais, levando-os a crer que não visualizaram tais imagens.

\section{A memória}

O termo memória tem sua origem etimológica no latim e significa: faculdade de reter e/ou readquirir idéias, imagens, expressões e conhecimentos, reportando-se às lembranças. Trata-se de faculdade cognitiva extremamente importante porque forma a base para a aprendizagem. Se não houvesse forma de armazenamento de representações mentais do passado, seria impossível obtermos benefício ou malefício da experiência. Assim, a memória envolve complexo mecanismo que abrange o arquivo e a recuperação de experiências. Portanto, está intimamente associada à aprendizagem, que é a habilidade de modificarmos nosso comportamento por meio das experiências que foram armazenadas na memória. Na verdade, a memória

\footnotetext{
${ }^{1}$ SCHACTER, 1996, citado em http://www.ateus.net.
} 
da maioria das pessoas é melhor do que elas imaginam. Qualquer que seja a definição, há sempre a idéia implícita de que a função da memória é representar o passado no presente e, ainda, a idéia de que quase todos se utilizam dela ${ }^{2}$. De acordo com Carter (2003, p. 316):

"Memória é a imagem que vem à mente quando você pensa na casa em que viveu quando criança; é a capacidade de saltar sobre uma bicicleta e pedalar sem precisar pensar em como fazê-lo; o sentimento de inquietação associado a um lugar onde algo assustador que lhe aconteceu no passado; refazer uma rota familiar; e o conhecimento que você guarda de que a Torre Eiffel fica em Paris".

Nem todos os aspectos de uma experiência são lembrados com a mesma facilidade, e a ampliação da memória, produzida pela excitação emocional, pode influenciar alguns aspectos mais do que outros ${ }^{3}$. Após um assalto, por exemplo, a vítima poderá lembrar-se do incidente com maior clareza do que de outros acontecimentos ocorridos no mesmo dia. Estudos de McGaught e colaboradores (1995) sugerem que o hormônio adrenalina, liberado durante o estresse, estabiliza e fortalece as memórias. Contudo, visto que, normalmente, a adrenalina não pode entrar no cérebro pela corrente sanguínea, a ação deve ser indireta. O diagrama mostra de que maneira a adrenalina pode exercer sua ação indireta no cérebro. Estímulos associados ao perigo ativam a amígdala. Por meio das vias que percorrem o hipotálamo lateral, até a medula lateral ventral rostral, o sistema nervoso autônomo é estimulado. Um dos inúmeros órgãos-alvo influenciados pela excitação do SNA é a medula supra-renal, que libera adrenalina, exercendo ação disseminada pelo corpo. O efeito sobre o nervo vago parece ser especialmente importante para a modulação da memória, o qual chega ao fim no núcleo do trato solitário (NTS), na medula. O NTS, por sua vez, envia informações ao locus coeruleus, que, então, libera noradrenalina em amplas áreas do prosencéfalo, incluindo-se aí a amígdala e o hipocampo. Influenciando as funções da amígdala e do hipocampo, as memórias emocionais implícitas e explícitas podem ser moduladas.

Cada tipo diferente de memória é armazenado e recuperado em caminho diferente, e dúzias de áreas do cérebro estão envolvidas numa complexa rede de interações ${ }^{4}$. Qualquer que seja o tipo de memória trata-se de associação entre um grupo de neurônios, no qual, quando um dispara, todos eles disparam, criando, assim, um padrão específico. Nesse disparo, quanto mais rápido, maior é a carga

\footnotetext{
${ }^{2}$ COTER, 1977.

${ }^{3}$ CARTER, 2003,p. 316.

${ }^{4}$ CHRISTIANSON, 1992, apudLEDOUX, 2001.
} 
elétrica que atira para fora, e maior é a probabilidade de deflagrar seu vizinho. Uma vez que o vizinho tiver sido incitado a disparar, ocorre alteração química na sua superfície que o deixa mais sensível à estimulação pelo mesmo vizinho. Tal processo é denominado de potencialização em longo prazo.

Se a célula vizinha não for novamente estimulada, permanecerá nesse estado de prontidão por horas, talvez, por dias. Se a primeira célula voltar a disparar durante o período, o vizinho poderá responder mesmo se a taxa de disparos da célula "número um" for relativamente baixa. O segundo disparo torna-a ainda mais receptiva, e assim por diante. Finalmente, a disparada sincrônica repetida une os neurônios de tal maneira que a atividade mínima em um fará com que todos aqueles associados a ele também disparem. Formou-se uma memória ${ }^{5}$.

James Brewer e seu grupo (1998) utilizaram a IFRM (Imagem Funcional da Ressonância Magnética) para investigar as áreas do cérebro responsáveis pela codificação de lembranças de imagens. Mostraram 96 imagens de cenas de interiores e de exteriores a seis participantes normais destros enquanto faziam uma varredura de seus cérebros. Depois, foram testados sobre a habilidade de lembrar-se dessas imagens. Os participantes claramente lembraram-se de cerca de um quarto das imagens, afirmaram que cerca de um quarto lhes parecia familiar, e esqueceram-se da metade. Os pesquisadores correlacionaram, então, a ativação da área cerebral medida no IFRM com a lembrança das imagens. Encontraram um par de áreas cerebrais que foram correlacionadas com o grau de memorização das imagens e deduziram que deveriam ser áreas cerebrais mais ativadas durante a codificação da memória, embora não necessariamente sejam as que realmente armazenam memórias. As áreas mais fortemente relacionadas com itens lembrados durante a codificação foram o córtex pré-frontal direito e o córtex para-hipocampal.

\section{Os mecanismos cerebrais da memória}

A localização da memória não se dá em estrutura isolada no cérebro; envolve um conjunto de sistemas cerebrais que funcionam juntos. O lobo temporal trata-se de uma região do cérebro que apresenta significativo envolvimento com a memória. Localizado abaixo do osso temporal, acima das orelhas, assim chamado porque os cabelos nesta região, freqüentemente, são os primeiros a tornaremse brancos com o tempo. Há evidências que apontam tal região como particularmente importante para armazenar eventos passados.

O lobo temporal contém o neocórtex temporal, que pode ser a região potencialmente envolvida com a memória de longo prazo. Nesta região, também há um

${ }^{5}$ CARTER, 2003. 
grupo de estruturas interconectadas entre si que exercem a função da memória para fatos e eventos, a memória episódica; entre elas, está o hipocampo, em que as estruturas corticais o circundam, e as vias que conectam estas estruturas a outras partes do cérebro.

O hipocampo ajuda a selecionar onde os aspectos importantes para fatos e eventos serão armazenados e está envolvido também com o reconhecimento de novidades e com as relações espaciais, tais como, o reconhecimento de uma rota rodoviária. A amígdala, por sua vez, é uma espécie de "aeroporto" do cérebro, a qual se comunica com o tálamo e com todos os sistemas sensoriais do córtex por meio de suas extensas conexões. Os estímulos sensoriais vindos do meio externo, como som, cheiro, sabor, visualização e sensação de objetos, são traduzidos em sinais elétricos e ativam um circuito na amígdala que está relacionado à memória, o qual depende de conexões entre a amígdala e o tálamo. Conexões entre amígdala e hipotálamo, onde as respostas emocionais provavelmente se originam, permitem que as emoções influenciem a aprendizagem, porque ativam outras conexões da amígdala para as vias sensoriais, por exemplo, o sistema visual.

O córtex pré-frontal exibe também papel importante na resolução de problemas e planejamento do comportamento. Uma razão para acreditar que o córtex préfrontal esteja envolvido com a memória é ele estar interconectado com o lobo temporal e o tálamo.

Para maior compreensão, os psicólogos da atualidade fizeram três distinções sobre a memória. A primeira refere-se aos três estágios da memória: codificação, armazenamento e recuperação. A segunda trata de diferentes memórias para armazenar informações por períodos longos e curtos. A terceira distinção é sobre diferentes memórias serem utilizadas para armazenar diferentes tipos de informação ${ }^{6}$.

\section{Estágios da memória}

Suponhamos que é apresentado à classe um professor de nome fictício Fernando Marques. Naquela tarde, um aluno vê-o novamente e cumprimenta-o, chamando-o pelo nome. Mas, como ele se lembrou do nome do professor? Primeiramente, quando o professor foi apresentado à turma, o aluno, de alguma forma, depositou o nome, Fernando Marques, na memória, constituindo o estágio de codificação; transformou um estímulo físico, as ondas sonoras que correspondem ao nome falado, em um tipo de código ou representação que a memória aceita, e "colocou" tal representação na memória. Segundo, ele reteve, ou armazenou, o nome durante o intervalo entre os dois encontros, sendo o estágio de

\footnotetext{
${ }^{6}$ ATKINSON, 2002.
} 
armazenamento. E, por último, resgatou o nome do armazenamento no momento de seu segundo encontro com o professor, sendo o estágio de recuperação. A memória pode falhar em qualquer um desses estágios. Se o aluno não conseguisse lembrar o nome do professor no segundo encontro, isso poderia ser reflexo de fracasso no estágio de codificação, no armazenamento ou na recuperação.

\section{Tipos de memória}

Os três estágios da memória não operam da mesma forma em todas as situações. A memória parece diferir entre situações que exigem armazenamento por questão de segundos daquelas que nos exigem armazenamento por intervalos mais longos, ou seja, de minutos a anos. Não existe o modelo perfeito para assimilar todos os aspectos da memória humana ${ }^{7}$. Portanto, um modelo eficaz na explicação das funções básicas da memória é chamado modelo de estágios de memória, diferindo na capacidade, duração e função.

Pesquisadores de memória têm proposto, pelo menos, três sistemas distintos de armazenamento de memória: memória sensorial, memória de curto prazo e memória de longo prazo. A memória sensorial refere-se ao armazenamento inicial da informação por meio dos sentidos, como uma imagem visual ou auditiva. A memória de curto prazo (MCP) é a operacional, na qual a informação é brevemente armazenada e processada. A memória de longo prazo (MLP) contém informação e experiências que foram armazenadas para uso no futuro ${ }^{8}$.

\section{Memória sensorial}

Considerada como primeiro estágio, a memória sensorial é aquela que armazena uma informação temporariamente, no nível os sentidos, tais como: paladar, tato, olfato e audição. Imagens visuais duram $1 / 2$ segundo, e o som, em torno de quatro segundos, tempo suficiente para re-analisar o que ouvimos, ou entender o que uma pessoa disse antes de a memória desaparecer completamente.

Quando você reenfoca um som ou imagem visual, que está na MCP, o espaço de trabalho para a atenção corrente onde as representações sensoriais podem ser interpretadas. Somente a informação selecionada para transformação em MCP recebe mais processamento e tem a chance de ser armazenada permanentemente 9 . Tal informação selecionada é importante porque é transferida para o segundo estágio, denominado de memória de curto prazo.

\footnotetext{
${ }^{7}$ TULVING, 1997, citado em HOCKENBURY, 2003.

${ }^{8}$ ATKINSON e SCHIFFRIN, 1968, citado em HUFFMAN, 2003.

${ }^{9}$ HUFFMAN, 2003.
} 


\section{Memória de curto prazo-memória operacional}

Consiste em memórias que são armazenadas por apenas alguns segundos ${ }^{10}$. Em geral, costuma-se selecionar eventos ou objetos para dar atenção. Porém, a memória de operação irá conter apenas aquilo que foi selecionado. Isso significa que grande parte dos estímulos expostos não estarão disponíveis para futura recuperação.

Quando a informação é codificada na memória, ela é registrada em algum código ou representação. Por exemplo, quando consultamos um número de telefone e o guardamos até discá-los, podemos utilizar uma representação visual, fonológica, semântica ou alguma associação que os números têm. Segundo Atkinson (2002), ensaiar é uma estratégia particularmente popular quando a informação consiste em itens verbais, como dígitos, letras ou palavras. Assim, ao lembrar um número de telefone, é mais provável que codifiquemos o número pelo som dos nomes dos dígitos e recitemos tais sons mentalmente até discarmos o número.

Em se tratando de armazenamento, a memória de operação possui capacidade limitada. Algumas pessoas armazenam pouquíssimos itens. Já outras são capazes de armazenar vários itens. O esquecimento ocorre ou porque os itens "decaem" com o passar do tempo, ou são substituídos por novos itens. A informação na memória de operação pode sumir no decorrer do tempo. Podemos pensar a representação de um item como um sinal que desaparece em questão de segundos ${ }^{11}$. Segundo o experimento de Sternberg (1966), citado em Atkinson (2002), foi demonstrado que, quanto mais itens existem na memória de operação, mais lenta tornase sua recuperação.

A memória de operação também ocorre com freqüência em processos de linguagem, como acompanhar uma conversa ou ler um texto. Quando lemos para compreender, devemos, conscientemente, relacionar as novas frases a algum material anterior no texto. Isso parece ocorrer porque as pessoas que têm maior capacidade de memória de operação obtêm melhores resultados do que outras em teste de compreensão de leitura ${ }^{12}$.

A memória de operação serve também como estação intermediária para a memória de longo prazo, ou seja, a informação pode residir na memória de operação enquanto está sendo codificada ou transferida para a memória de longo pra$\mathrm{zo}^{13}$. Além de o item determinado manter-se na memória de operação, também é transferido para a memória de longo prazo.

\footnotetext{
${ }^{10}$ ATKINSON, 2002.

${ }^{11}$ ATKINSON, 2002.

12 DANEMAN e CARPENTER, 1980; JUST e CARPENTER, 1992, apud ATKINSON, 2002.

${ }^{13}$ ARKINSON e SHIFFRIN, 1971; RAAIJMAKERS e SHIFFRIN, 1992, apud ATKINSON, 2002.
} 
Em suma, a memória de operação é utilizada para armazenar e processar informações necessárias durante a resolução de problemas e, portanto, é fundamental para o pensamento. Parte dessas informações podem ser codificadas e armazenadas na memória de longo prazo.

\section{Memória de longo prazo}

Ocorre no momento em que a informação precisa ser retida por intervalos curtos, algo dito numa conversa, ou durante toda a vida, memórias de infância de um adulto. Para material verbal, a representação dominante da memória de longo prazo não é acústica ou visual e, sim, baseada nos significados dos itens ${ }^{14}$. Após alguns minutos, depois de ouvir uma frase, a maior parte do que somos capazes de recordar é o seu significado. Já em casos de memorização de um poema, por exemplo, não codificamos apenas o significado, mas as palavras em si.

Durante a passagem da memória de curto prazo para a memória de longo prazo, a informação que chega é codificada para ser arquivada em seguida. Caso não seja codificada e arquivada de forma adequada, poderá não estar acessível no momento oportuno. Quanto maior a organização da informação, maior será a probabilidade de que permaneça armazenada na memória de longo prazo ${ }^{15}$.

Assim como nos mamíferos, a memória de uma mosca-das-frutas fica reforçada quando o condicionamento é repetitivo e realizado com um intervalo entre cada sessão. Segundo Hitier, Petit e Préat (2004), se uma mosca receber dez vezes um choque elétrico junto com um cheiro específico, a lembrança da associação passa para a memória de longo prazo e persiste por, pelo menos, uma semana. Para uma mosca-das-frutas em seu hábitat, isso significa praticamente toda a sua vida.

Parte do trabalho de organização e arquivamento da memória, aparentemente, ocorre durante o sono. Alguns pesquisadores acreditam que, durante o sono REM, adições recentes à memória de longo prazo são revistas, aperfeiçoadas e, sistematicamente, catalogadas ${ }^{16}$.

Os casos de esquecimento da memória de longo prazo ocorrem em decorrência da perda da informação propriamente dita. Por ser uma memória fraca, reflete falha de armazenamento. Segundo Arkinson (2002), tentar recuperar um item na memória de longo prazo é como tentar encontrar um livro em uma grande biblioteca.

\footnotetext{
${ }^{14}$ ARKINSON, 2002.

${ }^{15}$ HUFFMAN, 2001.

${ }^{16}$ CRICK e MITCHISON, 1983; HENNEVIN et al.., 1995, apud HUFFMAN, 2003.
} 
A MLP pode ser dividida em memória semântica, memória episódica e memória procedural:

\section{a) Memória semântica}

Abrange a memória do significado das palavras, ou seja, o conhecimento dos fatos e como eles se relacionam entre si. Trata-se da co-participação partilhada do significado de uma palavra que possibilita às pessoas manter conversas com significado. Segundo Huffman (2003), é como uma enciclopédia de informações factuais, como os nomes dos meses, como 2 × 2 são 4, e como a capital da Índia é Nova Déli, pois torna-se um conteúdo duradouro após sua armazenamento. A informação semântica é, portanto, armazenada na memória de longo prazo sem lembrar quando ou onde foi originalmente encontrada tal informação.

De um modo geral, os testes referentes à memória semântica são constituídos por perguntas respondidas em termos de conhecimento existente, ao invés de experiências individuais específicas. Acredita-se que a memória semântica forneça um esquema geral de nós mesmos e do que fizemos em épocas distintas, fornecendo, assim, uma resposta precisa, sob o ponto de vista genérico, à pergunta ${ }^{17}$.

\section{b) Memória episódica}

Contém informações "autobiográficas" que consistem em quando e onde um evento específico ou episódio ocorreu. Refere-se aos eventos datados, ou seja, relacionados com o tempo, como, por exemplo, quando lembramos o ataque terrorista em 11 de setembro.

Muitos pesquisadores têm tentado experimentalmente separar os dois tipos de MLP, mas, sem sucesso ${ }^{18}$. Tulving $(1985,1986)$ sugere que as duas são inseparáveis porque a memória episódica é, na realidade, um subsistema da memória semântica. Em qualquer dos casos, a distinção entre a memória semântica e a episódica é útil no estudo da memória.

c) Memória procedural ou memória de procedimentos

Refere-se a tudo que armazenamos para desempenhar diferentes habilidades, operações e ações. Exemplos de memória procedural podem ser: dirigir, correr, digitar, andar de bicicleta, entre outros, os quais são formados desde o momento em que passamos a falar, andar, comer, etc.

Com freqüência não lembramos exatamente quando e como aprendemos as informações procedurais. Em geral, é difícil descrever memórias procedurais em palavras. Por exemplo, tente descrever de forma precisa e exata o que você faz

${ }^{17}$ COTER, 1977.

${ }^{18}$ MCKOON et. al.,1986; NEELY e DURGUNOGLU, 1985; RICHARDS e GoLDFARB, 1986, apud HUFFMAN. 
quando usa um secador de cabelo, quando toca violão ou anda de bicicleta. Você vai ver que não é tão fácil como pensa. Uma habilidade específica pode ser fácil demonstrar, mas muito difícil descrever ${ }^{19}$.

\section{Memória implícita ou não-declarativa}

A memória implícita trata de tudo aquilo que lembramos quando fazemos algo. Inclui habilidades motoras e sensoriais, hábitos e aprendizado emocional e formas elementares de aprendizado reflexo, tais como, habituação, sensibilização e condicionamentos clássico e operante. Assim, a memória não-declarativa envolve conhecimento de natureza reflexa, mas que não exige reflexão ${ }^{20}$. Diferentes formas de memória implícita são adquiridas por meio de diferentes regiões do cérebro. A memória adquirida por meio do condicionamento pelo medo, por exemplo, tem componente emocional e envolve a amígdala ${ }^{21}$.

\section{Memória explícita ou declarativa}

É utilizada para eventos, fatos, palavras, faces, música, etc. Um exemplo seria quando falamos em trazer à mente um evento passado, como a lembrança de um amigo ou um pensamento passageiro sobre um evento ocorrido anteriormente no mesmo dia, falamos da memória em seu sentido mais comum, que nos é familiar, como uma recordação consciente. A memória explícita é, portanto, o conhecimento factual de pessoas, lugares e coisas e o que esses fatos significam. Assim, é extremamente flexível e envolve a associação de diversos pedaços e peças de informação ${ }^{22}$.

A distinção entre a memória explícita e implícita foi bem demonstrada em pesquisa realizada por Squire e colaboradores (1984). Verificaram que os amnésicos poderiam ser induzidos ao sucesso ou ao fracasso num teste de memória com a simples alteração das instruções: algumas delas conduziram os pacientes para a via da memória explícita, redundando em fracasso, enquanto outras os levaram a um passeio bem-sucedido pelo universo da memória implícita. Os estímulos foram os mesmos em todos os casos, somente as instruções de memória foram modifica$\operatorname{das}^{23}$.

${ }^{19}$ HOCKENBURY, 2003.

${ }^{20}$ SQUIRE e KANDEL, 2003.

${ }^{21}$ KANDEL, SCHWARTZ e JESSELL, 2003.

${ }^{22}$ KANDEL, SCHWARTZ e JESSELL, 2003.

${ }^{23}$ LEDOUX, 2001. 


\section{Distúrbios da Memória}

\section{Amnésia}

Amnésia trata-se de ausência de imagens mnêmicas, originárias dos sentidos (visual, auditivo, olfativo, gustativo, tátil, verbal) de um dado período da vida de uma pessoa. Não é uma condição simples, pode variar em decorrência de várias dimensões, ou seja, o distúrbio pode ser temporário ou essencialmente irreversível. Pode-se perder pequena ou grande parte da memória, e, quanto mais intenso for o choque no cérebro, maior será o espaço de tempo de esquecimento ${ }^{24}$. Se um jogador for atingido por uma bola de basquete, poderá permanecer com amnésia por alguns segundos. Já uma pessoa deprimida que está sob terapia eletroconvulsiva pode perder a memória por vários dias; pessoas que sobreviveram a ferimentos graves na cabeça poderão perder a memória por dias, meses ou anos.

A amnésia é dividida em dois tipos: amnésia anterógrada e amnésia retrógrada:

a) Amnésia anterógrada - Refere-se ao esquecimento dos fatos transcorridos depois da causa determinante do distúrbio, ou seja, a pessoa possui dificuldade no processamento de eventos que ocorreram após o incidente porque os processos de memória não estão trabalhando de forma eficiente ${ }^{25}$. Costuma ocorrer em decorrência de concomitante perturbação da atenção, tanto da tenacidade quanto da vigilância.

A maioria dos casos deve-se a alterações orgânicas, como se houvesse diminuição da receptividade do sistema nervoso aos estímulos. Tal amnésia, portanto, pode ser observada em lesões cerebrais agudas ou crônicas, por causas traumáticas, circulatórias ou tóxicas. Os portadores de amnésia anterógrada não podem relembrar os fatos recentes, porém, conservam a capacidade para recordar acontecimentos passados mais remotamente.

b) Amnésia retrógrada - Ocorre quando há perda da memória para os fatos ocorridos antes do evento que o causou, ou seja, a pessoa possui dificuldade de lembrar-se de eventos que ocorreram antes do incidente traumático ${ }^{26}$. O dano cerebral, de qualquer natureza, tem destaque principal entre as causas. Tal tipo de amnésia pode durar dias ou semanas anteriores à lesão. Em alguns casos raros, pode compreender todos os acontecimentos anteriores à vida do indivíduo.

\footnotetext{
${ }^{24}$ DAVIDOFF, 2001.

${ }^{25}$ HUFFMAN, 2003.

${ }^{26}$ HUFFMAN, 2003.
} 
A amnésia retrógrada é observada nos quadros neuro-psicológicos senis, após um ictus circulatório cerebral e nos traumatismos cranianos, em especial, quando há perda de consciência. Apesar de tal sintomatologia, a amnésia retrógrada pode ser reversível, em que ocorre a regressão dos fatos mais antigos para os mais recentes ${ }^{27}$.

\section{Hipermnésia}

É o aumento da capacidade de evocação tanto de dados do reservatório da memória como de dados que permaneciam esquecidos. Pode ocorrer em decorrência de emoções intensas, quando a pessoa sente a morte, com delírios de febre, com a hipnose, entre outros.

As memórias emocionalmente intensas e significantes para o indivíduo não representam, necessariamente, verdade histórica. A melhora da memória para eventos passados é ilusória porque sugestões de hipermnésia aumentam a falsa recordação e a confiança do indivíduo tanto nos eventos da memória verdadeira como nos da memória falsa ${ }^{28}$. Pessoas que foram salvas da morte iminente por afogamento descrevem que, no momento da asfixia, pareciam ver toda a vida anterior desenrolando-se em sucessão e com pormenores muito precisos, formando um panorama de toda existência ${ }^{29}$.

\section{Amnésia infantil}

Freud foi o primeiro a discutir a amnésia infantil depois de observar que, comumente, por volta dos dois anos, a criança já sabe falar bem e está familiarizada com situações mentais complicadas e, no entanto, se, mais tarde, falarem-lhe de algum comentário feito nessa época, ela não terá qualquer lembrança a respeito.

Uma região do cérebro, para tornar-se completamente funcional, precisa desenvolver suas células e interligá-las a outras das demais regiões. O hipocampo, por sua vez, necessita de período de tempo maior para adquirir maturação. Em vista disso, Jacobs e Nadel (1985), apud LeDoux (2001), propuseram que não temos lembranças explícitas da primeira infância porque o sistema que as produz não está pronto para realizar o seu trabalho. Outros sistemas cerebrais, contudo, devem estar preparados para o aprendizado e a recordação desde logo, pois as crianças

\footnotetext{
${ }^{27}$ BALLONE, 2004.

${ }^{28}$ FERREIRA, 2003.

${ }^{29}$ BALLONE, 2003.
} 
aprendem durante o período da amnésia, ainda que não tenham lembranças conscientes do aprendizado.

\section{Síndrome de Korsakoff}

Korsakoff, médico russo, foi o primeiro a descrever uma síndrome habitualmente encontrada em pacientes alcoólicos crônicos, da qual um dos sintomas é a perda quase completa da memória. Segundo Sacks (2002, p.55): “A síndrome de Korsakoff clássica - uma devastação da memória grave e permanente, mas 'pura', causada pela destruição alcoólica dos corpos mamilares - é rara, mesmo entre pessoas que bebem muito".

Um estudo cuidadoso dos cérebros de pacientes com a síndrome de Korsakoff revelou proporções variáveis de danos cerebrais, com lesões no tálamo médio, comuns aos pacientes que haviam sofrido perda de memória mais séria ${ }^{30}$. Muitos pacientes apresentavam deterioração mental considerável, além da perda de memória, mas alguns se conservavam bastante inteligentes. O paciente original de Korsakoff era capaz de jogar bem uma partida de xadrez, embora fosse incapaz de lembrar o que o levara a adotar as posições sobre o tabuleiro em determinado momento ${ }^{31}$.

\section{Doença de Alzheimer}

Alois Alzheimer (1864-915), médico alemão, ao realizar autópsia, descobriu no cérebro, lesões jamais vistas antes. Desde então, este tipo de degeneração nos neurônios ficou conhecida como Doença de Alzheimer.

O mal de Alzheimer, segundo Huffman (2003), trata-se de deterioração mental progressiva que ocorre com maior freqüência em idades mais avançadas. Os sintomas mais comuns são distúrbios da memória, que se iniciam com esquecimentos leves e, conforme sua evolução, a pessoa falha em reconhecer pessoas familiares, fica desorientada, passa a ter dificuldades de tomar decisões e até de conversar, necessitando de cuidados especiais e, por fim, morre.

É comum pessoas queixarem-se das falhas de memória e do pouco que conseguem lembrar-se daquilo que aprendem anteriormente. Algumas pessoas admitem que são especialistas em esquecer as coisas e possuem deficiência de memória. Outras, ainda, buscam cursos com objetivo de melhorar a memória. Isso indica que a memória é alvo importante das preocupações de homens e mulheres.

${ }^{30}$ ADAMS, COLLINS \& VICTOR, 1962, apud MILNER, 1970.

${ }^{31}$ MILNER, 1970. 


\section{Pecados da memória}

A memória desempenha papel extremamente importante no nosso cotidiano; muitas vezes, só temos consciência disso quando ocorre um incidente provocado em função de um esquecimento ou distorção que exige nossa atenção. Psicólogos e neurocientistas já escreveram artigos sobre aspectos específicos do esquecimento ou sobre as distorções da memória, mas não existe um só estudo que tenha conceituado os vários modos como, às vezes, a memória pode enganar$\operatorname{nos}^{32}$.

As falhas da memória podem ser classificadas em sete transgressões ou "pecados" fundamentais: transitoriedade, distração, bloqueio, atribuição errada, sugestionabilidade, distorção e persistência. Em analogia aos sete pecados capitais, os pecados da memória podem ocorrer com freqüência no dia-a-dia e resultarem em consequiências desastrosas. Os sete pecados fazem com que compreendamos por que a memória funciona tão bem na maioria das vezes e por que evoluiu ao modelo atual ${ }^{33}$.

\section{O pecado da transitoriedade}

A transitoriedade está intimamente ligada ao enfraquecimento da memória com o passar do tempo. Segundo a ocorrência de novas experiências, o passado desaparece de forma inevitável, podendo causar situações constrangedoras. Recordações de data, local e nome de pessoas são alguns exemplos de transitoriedade.

A descoberta de Ebbinghaus, em 1878, de que a maior parte do esquecimento ocorre em períodos recentes ao acontecimento e que, depois, vai diminuindo foi comprovada em experiências de laboratório. Pesquisas recentes da memória também comprovaram que a curva gráfica do esquecimento formulada por Ebbinghaus pode ser aplicada fora dos limites do laboratório e demonstram que representa a estrutura básica da transitoriedade ${ }^{34}$.

A codificação da informação ligada à memorização ou ao esquecimento posteriores dá-se por meio da ativação da região inferior esquerda do lobo frontal. Assim, estudos indicaram que o hemisfério direito é responsável pela assimilação de imagens, enquanto o esquerdo, pelo processamento de palavras.

\footnotetext{
${ }^{32}$ SCHACTER, 2003.

${ }^{33}$ SCHACTER, 2003.

${ }^{34}$ SCHACTER, 2003.
} 
Em relação à idade, os problemas com a recordação de histórias começam por volta dos quarenta anos, mas a constância é mais definida quando as pessoas atingem a faixa dos sessenta e setenta anos. Isso ocorre porque as pessoas analisam ou arquivam novas informações, ou seja, quanto mais se analisa durante a codificação, menos transitórias são as lembranças.

Segundo nossa hipótese, a região esquerda do para-hipocampo ajudaria, então, a "arquivar" a análise na memória. Trabalhando juntas, essas duas partes do cérebro ajudariam a transformar a percepção de uma palavra em recordação duradoura ${ }^{35}$.

O principal responsável pela transitoriedade rápida é uma parte do sistema de memória operacional chamada "alça fonológica", que permite que guardarmos, temporariamente, pequenas quantidades de informação lingüística. Trata-se de subsistema "escravo" que ajuda o sistema "executivo central" da memória operacional e controla o fluxo de informação para dentro e para fora da memória de longo prazo $^{36}$.

Quando adquirimos nova informação, ocorrem mudanças químicas complexas nas conexões (sinapses) que ligam os neurônios entre si. De acordo com estudos, com o passar do tempo, tais alterações tendem a atenuar-se. As conexões neurais que codificam as lembranças podem, então, enfraquecer-se com a passagem do tempo, repetindo o traçado da curva de deterioração registrado pela primeira vez por Ebbinghaus (1885). Caso não sejam reforçadas por esforço posterior de recuperação e repetição da informação, as conexões ficam mais fracas, e a memória acaba obstruída ${ }^{37}$.

Todos gostariam de lembrar-se mais do que o que está na transitoriedade. Qualquer tentativa de reduzi-la é válida, levando em consideração o processo de codificação da memória. Livros, artigos e até programas de TV fornecem técnicas de memorização, mas a mais recomendada envolve algum método mnemônico de visualização de imagens, ou seja, as pessoas são incentivadas a elaborar a informação que desejam lembrar, transformando-a em imagem vívida.

\section{O pecado da distração}

O pecado da distração está ligado ao esquecimento da informação que não chegou a ser codificada de forma adequada ou está armazenada na memória, mas mostra-se indisponível no momento em que tentamos invocá-la.

\footnotetext{
${ }^{35}$ SHACTER, 2003.

${ }^{36}$ BADDELEY, 1998, apud SCHACTER, 2003.

${ }^{37}$ SCHACTER, 2003.
} 
A falta de atenção na hora de codificar uma informação pode ser fator especialmente importante para os erros de distração cometidos por adultos ${ }^{38}$. Ao dividir-se a atenção, ocorre redução geral da quantidade de recursos cognitivos (o "combustível" que alimenta a codificação) que podem ser canalizados para as novas informações a serem assimiladas ${ }^{39}$. Mas, à medida que a habilidade aumenta com a prática, menos atenção deve ser desprendida, como, por exemplo, dirigir um automóvel.

Níveis automáticos ou superficiais de codificação podem provocar erros da memória relacionados à distração. Um dos mais intrigantes é conhecido como "cegueira para mudança". Em estudos sobre a cegueira para mudança, voluntários observam objetos ou cenas que se desenvolvem ao longo de um período de tempo. Os aplicadores do teste fazem mudanças sutis ou grandes nos objetos ou cenas para ver se os voluntários as observam. A cegueira para mudança ocorre quando os voluntários não conseguem detectar as mudanças ${ }^{40}$.

De acordo com a explicação de Simons (1999) e equipe, as pessoas tendem a detectar mudanças quando codificam de forma elaborada as características exatas que distinguem o objeto original, ou pessoa, do objeto ou pessoa que foram trocados. Portanto, a codificação superficial que não processa informações além de nível mais geral, resulta em memorização fraca de detalhes de uma cena e conseqüente vulnerabilidade à cegueira para mudança.

As pessoas, em geral, manifestam preocupação maior em lembrar coisas que precisam realizar no futuro (memória prospectiva) do que com aspectos passados da memória (memória retrospectiva). Tal distinção ocorre em decorrência do fato de que, quando a memória retrospectiva falha (quando se esquece de um nome, ou se confundem datas e locais de dois acontecimentos), a pessoa é vista como pouco confiável. Já a falha da memória prospectiva (quando se esquece um almoço, pagamento ou entrega de uma encomenda) leva à falta de confiança, além de refletir em credibilidade e caráter.

Em relação à idade, estudos de laboratório demonstraram que adultos mais velhos, que chegaram aos sessenta e setenta anos de idade, desempenham tarefas de memória prospectiva baseadas em eventos quase tão bem quanto adultos mais jovens. Quando recebem uma pista, uma associação que os lembre de realizar tarefa específica, os mais idosos têm pouco ou nenhum problema para lembrar o que precisam fazer ${ }^{41}$. O uso de métodos mnemônicos pode ser eficaz na redução

\footnotetext{
${ }^{38}$ SCHACTER, 2003.

${ }^{39}$ CRAIK; JACOBY, 1996, apud SCHACTER, 2003.

${ }^{40}$ LEVIN; SIMONS, 1998, apud SCHACTER, 2003.

${ }^{41}$ SCHACTER, 2003.
} 
ou eliminação das falhas de distração em especial, na memória prospectiva, pois requer pistas e associações que fazem com que as pessoas se lembrem daquilo que pretendiam fazer.

\section{O pecado do bloqueio}

O pecado do bloqueio trata-se de uma busca de informação que se encontra escondida, aparentemente pronta para voltar à mente com um pouco mais de esforço. Nomes de pessoas conhecidas são exemplos de bloqueios mais freqüentes.

O pecado do bloqueio envolve um tipo de esquecimento que se distingue da distração e da transitoriedade. Ao contrário das falhas da memória relacionadas à distração, o nome ou a palavra recalcitrante que você não consegue lembrar foram codificados e armazenados na mente e pode existir uma pista ou associação que faria você se lembrar ${ }^{42}$.

A noção de que nomes próprios de pessoas são difíceis de lembrar pode ser explicada pelo fato de revelarem pouco a respeito das características de seus portadores. Entretanto, quando se trata de nomes próprios, cada uma das representações conceituais converge individualmente para representação única especial da identidade de uma pessoa, batizada de "nodo de identidade da pessoa"43. Desse modo, a representação conceitual "ator" é conectada por meio de ligação com um nodo de identidade da pessoa, a "Mel Gibson". Da mesma forma, as representações conceituais: "diretor de cinema" e "gosta de cozinhar" são conectadas ao nodo de identidade dessa pessoa. É assim que todas as informações diferentes que temos sobre "Mel Gibson" convergem para identificá-lo.

Segundo o modelo de Burke e MacKay (1991), os nomes mais suscetíveis ao bloqueio de memória são os familiares de pessoas que não encontramos recentemente. $\mathrm{O}$ encontro com uma pessoa ativa as representações tanto conceituais como léxicas relacionadas a ela e, dessa forma, reforça as conexões entre tais representações. Ao contrário disso, quando deixamos de ver uma pessoa por um longo período de tempo, o elo entre as representações léxicas e conceituais, que já é frágil, fica ainda mais enfraquecido.

Schacter (2003) exemplifica o bloqueio com o caso de uma mulher de vinte anos que se declarou inocente perante um tribunal em Toronto por ter assassinado seu bebê de 23 dias. A mãe afirmava que havia tropeçado no fio da televisão a cabo e que o bebê caíra no chão. O fato interessante é que ela não havia mencionado coisa alguma sobre tal acidente quando interrogada pela polícia, logo após a morte do bebê. Durante o julgamento, explicou que estava "em estado de cho-

${ }^{42}$ SCHACTER, 2003. 
que", em resultado do fato e o havia "bloqueado" da sua memória. Acrescentou que, somente após alguns meses, recuperou a memória, quando estava vendo algumas fotos do bebê. Segundo o psiquiatra Graham Glancy, a intensidade da tragédia sofrida pode ter tornado a mãe mais vulnerável à amnésia. Casos como este são raros, pois ocorrem quando há algum problema físico com o cérebro, como ferimentos na cabeça, drogas, bebidas alcoólicas ou perda de consciência, quando não se consegue lembrar do trauma acontecido recentemente.

O psicólogo Michael Anderson, da Universidade de Oregon, formulou a teoria de que todas as vezes que recuperamos lembranças seletivas em resposta à determinada pista, mas não a outras pistas, ocorre uma inibição de informações não recordadas. Estudos com pessoas que afirmam terem sofrido abuso sexual na infância indicam, surpreendentemente, que os casos de esquecimento temporário do fato são mais comuns quando o agressor é alguém da família. Quando um dos pais ou outra pessoa de confiança é responsável pelo abuso sexual, a criança ainda é dependente emocional e fisicamente e, por causa disso, precisa continuar a manter uma relação com o agressor. A lembrança do abuso pode atrapalhar esse objetivo ao criar ansiedade e desconfiança. Já a recordação de experiências mais positivas com a pessoa em questão pode facilitar a adaptação à relação. Portanto, a criança precisa recordar seletivamente experiências não traumáticas, ao invés de traumáticas, associadas à pessoa de confiança. Esse tipo de situação pode promover a inibição induzida pela lembrança: quando precisamos recuperar certas lembranças em resposta a pista específica (nesse caso, a pessoa da família), mas não a outras ${ }^{44}$. Enquanto não captamos todas as dificuldades, estudos de neuroimagem contribuem significativamente para a compreensão do bloqueio.

\section{O pecado da atribuição errada}

Algumas vezes, lembramos fatos que jamais ocorreram, atribuindo erroneamente o processamento rápido de novas informações ou imagens vívidas que nos vêm à mente a lembranças de eventos passados que não aconteceram. A isto damos o nome de atribuição errada. Como exemplo, temos a atribuição errada de testemunhas, ou seja, uma testemunha que atribui a familiaridade de um rosto à fonte errada.

Os psicólogos referem-se a esse processo de ligação como o problema da "cimentação da memória": a colagem, o agrupamento de vários componentes de uma experiência para formar um todo unitário. Quando as partes individuais de

${ }^{43}$ YOUNG et al., 1985, apud SCHACTER, 2003.

${ }^{44}$ ANDERSON, 1996, apud SCHACTER, 2003. 
uma experiência são retidas, mas a ligação da memória não acontece, estão criadas as condições para a atribuição errada de fonte e em outros episódios de recordação equivocada de testemunhas ${ }^{45}$.

Alguns estudos demonstraram que, quando as pessoas imaginam que estão realizando uma ação ou vendo um objeto, afirmam futuramente que realmente o fizeram. Uma forte sensação de familiaridade, juntamente com a falta de recordações específicas, cria a receita fatídica para o surgimento da atribuição errada. A compreensão desse ponto pode ser a chave para a redução das consequiências infames da atribuição errada nos depoimentos de testemunhas de um crime ${ }^{46}$.

Para minimizar o impacto desses julgamentos relativos, pode-se pedir que a testemunha tome uma decisão de culpa ou não imediatamente após ter visto cada um dos suspeitos, em vez de esperar que todos os suspeitos sejam mostrados ${ }^{47}$. Esse método incentiva as pessoas a investigar sua memória com mais cautela e, assim, verificar melhor se o suspeito mostrado se identifica com os detalhes de suas recordações. Segundo Schacter, é fácil fazer com que as pessoas tenham lembranças verdadeiras durante um exame de imagens do cérebro. Basta pedir que respondam a perguntas sobre palavras ou imagens mostradas antes do exame ou fazer perguntas sobre experiências do passado fora do laboratório.

Com base em experimentos, formulou-se a teoria de que o estudo de imagens junto com as palavras ajudou os participantes do estudo a recorrer a uma "heurística de distinção": uma norma prática que leva as pessoas a exigir da memória detalhes distintos de uma experiência antes de afirmar que dela se lembram ${ }^{48}$. Recorremos à heurística de distinção quando esperamos que nossa memória contenha informações detalhadas a respeito de uma experiência.

Outro tipo de atribuição errada é conhecido como "criptominésia", a qual pessoas atribuem erradamente a sensação de novidade a algo ou alguém que deveria ser familiar. Pesquisas sugerem que tal atribuição pode ser reduzida quando se orientam as pessoas a prestarem atenção à fonte de suas idéias. Muitas vezes precisamos resolver ambigüidades, como imagens passageiras ou sensações de familiaridades, que podem ter sua origem em experiências passadas ou terem sido criadas com base em influências sutis no presente.

\section{O pecado da sugestionalidade}

A sugestionabilidade na memória pode ser descrita como tendência do

\footnotetext{
${ }^{45}$ SCHACTER, 2003.

${ }^{46}$ SCHACTER, 2003.

${ }^{47}$ WELLS, 1998, apud SCHACTER, 2003.

${ }^{48}$ SCHACTER \& ISRAEL, 1999.
} 
indivíduo a assimilar informações enganadoras de fontes externas - outras pessoas, material escrito ou imagens, até mesmo os meios de comunicação - a recordações pessoais. A sugestionabilidade está bastante próxima da atribuição errada no sentido de que a transformação de sugestões em lembranças erradas deve envolver a atribuição errada ${ }^{49}$.

Perguntas tendenciosas podem levar testemunhas a identificar erradamente um suspeito; técnicas terapêuticas sugestivas podem ajudar a criar falsas lembranças; interrogatórios agressivos de crianças podem levá-las a ter lembranças distorcidas de abusos que jamais ocorreram. A distorção da memória é resultado de sugestões que fornecem informações gritantemente erradas ${ }^{50}$. Com objetivo de extrair o maior número de informações verdadeiras das testemunhas, alguns policiais defendem o uso de hipnose.

Outro método eficaz é conhecido como "entrevista cognitiva", que é baseada em descobertas e idéias comprovadas em estudos controlados de memória e evita, especificamente, o uso de perguntas sugestivas ou tendenciosas ${ }^{51}$. Entretanto, assim como a hipnose, a entrevista cognitiva pode produzir um número maior de relatos de informações incorretas. Algumas confissões falsas ocorrem pelo fato de suspeitos quererem acabar com a pressão psicológica, ou seja, abusos físicos ou mentais, mesmo que saibam que não cometeram o crime. Já outros, pelo desejo de chamar a atenção ou por serem portadores de algum distúrbio. O professor Hugo Munsterberg, da Universidade de Harvard, observou que a tensão emocional combinada às pressões sociais e à sugestão pode distorcer a memória até o ponto em que as pessoas acreditam erroneamente que cometeram um crime. Por outro lado, alguns podem ser especialmente suscetíveis a confissões falsas porque são muito sugestionáveis.

Um experimento divulgado no Discovery Health, exibido no dia 07 de julho de 2004, demonstrou que as confissões falsas podem não ser tão anormais como parecem de início. Estudantes universitários posicionados em frente a um computador foram orientados a digitar uma série de letras ditadas; um grupo digitava mais rápido, e outro mais, devagar. Todos os estudantes foram instruídos a não utilizar a tecla ALT do teclado. Caso isso ocorresse, provocaria pane no sistema. $\mathrm{O}$ resultado mostrou que nenhum dos estudantes utilizou a tecla, mas o experimentador do teste acusou-os falsamente de terem-no feito. Após negarem a acusação, metade dos estudantes em cada grupo ouviu uma "testemunha" dizer que havia visto o erro. Não houve "testemunha" para a outra metade. Quase todos os estudantes acabaram assinando um documento falso que comprovava o

\footnotetext{
${ }^{49}$ SCHACTER, 2003.

${ }^{50}$ LOFTUS, 1995, apud SCHACTER, 2003.

${ }^{51}$ FISHER E GEISELMAN, 1980, apud SCHACTER, 2003.
} 
uso da tecla ALT. O efeito foi marcante especialmente no grupo que digitou de forma mais rápida e também ouviu a testemunha apoiar o experimentador; todos assinaram a confissão, e alguns ainda descreveram detalhes, mas falsos, de como cometeram o erro.

Os efeitos perniciosos da sugestionabilidade reforçam a teoria de que lembrar o passado é mais do que simples ativação de vestígio dormente ou de imagem na mente. Envolve interação muito mais complexa entre o ambiente atual, o que se espera recordar e o que ficou guardado do passado. Os métodos sugestivos afetam o equilíbrio desses três fatores, de forma que as influências do presente desempenham papel bem mais importante na determinação do que é lembrado do que aquilo que realmente aconteceu no passado ${ }^{52}$. Quando sugestões provocadas pela hipnose, por exemplo, são utilizadas para resgatar memórias do passado, constituem forma altamente nociva para a produção de falsas memórias.

\section{O pecado da distorção}

As lembranças do passado podem ser redefinidas para se adequarem às nossas opiniões e necessidades do mundo atual. O pecado da distorção reflete as influências que modificam opiniões, conhecimentos e sentimentos do presente de novas experiências ou últimas recordações de tais lembranças.

Cinco tipos de distorção ilustram a maneira como a memória serve aos seus donos. As distorções de coerência e de mudança mostram como nossas teorias a respeito de nós mesmos podem levar-nos a reconstruir o passado de forma predominantemente parecida ao presente ou diferente dele. As distorções de hindsight (compreensão tardia) revelam que as recordações de eventos do passado são filtradas por conhecimentos atuais. As distorções egocêntricas ilustram a função poderosa do ego na criação de imagens e lembranças da realidade. As distorções estereotipadas demonstram como as lembranças genéricas moldam a interpretação do mundo, mesmo quando não estamos conscientes da sua existência ou influência ${ }^{53}$.

Muitas vezes, as pessoas não têm lembranças claras e exatas sobre o que achavam ou sentiam no passado. Em vez disso, tiram conclusões sobre opiniões, atitudes e sentimentos do passado com base no que aconteceu no presente ${ }^{54}$. Pessoas casadas e casais de namorados são exemplos de tais distorções ao compararem suas vivências do passado com o presente. Gostam de acreditar que seus relacionamentos ficam mais fortalecidos com o passar do tempo.

\footnotetext{
52 SCHACTER, 2003.

${ }^{53}$ SCHACTER, 2003.

${ }^{54}$ ROSS, 1989, apud SCHACTER, 2003.
} 
As distorções de coerência possuem a vantagem de ajudar a reduzir a "dissonância cognitiva", ou seja, o desconforto psicológico decorrente de pensamentos e sentimentos de conflito. Por exemplo, quando somos obrigados a escolher apenas um vestido entre os dois de que gostamos, depois de feita a escolha, podemos afirmar que gostamos mais do vestido escolhido e menos do outro. Já na distorção de compreensão tardia, reconstruímos o passado para torná-lo coerente com o que sabemos no presente. As pessoas ficam mais convencidas de que sempre souberam que um time de futebol ia ganhar quando podem encontrar uma causa que faça com que o resultado pareça inevitável.

Na distorção egocêntrica, a tendência é acreditar mais nas próprias lembranças do que nas de outros. Refletem a importância do papel do ego na organização e regulação da atividade mental. Já as distorções estereotipadas são ativadas de forma automática em pessoas que possuem poucos preconceitos. Às vezes, as pessoas agem de acordo com tais distorções em casos injustificáveis em que indivíduos são vistos de forma negativa porque pertencem a um grupo e não por causa do seu comportamento ou características, sendo, portanto, um "culpado por associação", conforme descreve Banaji (1999). Devemos assim, aceitar que conhecimento, opiniões e sentimentos atuais podem influenciar em nossas lembranças do passado e moldar nossas impressões a respeito de pessoas e objetos no presente.

\section{O pecado da persistência}

O último pecado da memória, a persistência, ao contrário da transitoriedade, da distração e do bloqueio, que refletem no esquecimento de informações que as pessoas querem lembrar, faz com que se lembrem de fatos que querem esquecer. Segundo Schacter (2003, p.200): "Experiências que lembramos sem querer, apesar de desejar desesperadamente afastá-las de nossa mente, estão intimamente ligadas, e algumas vezes são uma ameaça, à nossa imagem de quem somos e de quem gostaríamos de ser".

A persistência está estritamente relacionada com a emoção. Experiências do dia-a-dia e estudos revelam que acontecimentos com alta carga emocional são mais lembrados do que os que não são vivenciados com tal emoção. O efeito da emoção, segundo Schacter (2003), começa no momento em que a memória é criada, quando a atenção e a codificação determinam se uma experiência vai ser lembrada ou esquecida.

Quando conseguimos atingir nossos objetivos, sejam de curto ou longo prazo, sentimo-nos felizes e satisfeitos. Ao contrário disso, se algo que desejávamos não foi adquirido ou conquistado, ficamos tristes e frustrados. Assim, se 
relacionamos um fato presente com nossos objetivos, estamos fazendo reflexão ou análise, e isso proporciona a memorização dessa experiência. Se um homem é abordado por um ladrão armado, possivelmente, ao ser interrogado pela polícia, trará maiores detalhes a respeito da arma e da face do sujeito.

Memórias persistentes provocam conseqüências graves de todo tipo de experiência traumática, tais como: estupros, acidentes automobilísticos, guerra, abuso sexual, terremotos, tortura, entre outros. Problemas psicológicos futuros também podem acontecer quando a pessoa tenta evitar pensar sobre um acontecimento traumático imediatamente após esse evento. A dor causada por uma experiência traumática e pelas decorrentes memórias intrusivas associadas leva as pessoas a tentar evitar lembranças do incidente e, se possível, reprimir pensamentos e memórias relacionadas ao trauma ${ }^{55}$.

O pecado da persistência leva-nos a crer que as memórias intrusivas devem ser reconhecidas, enfrentadas e resolvidas a fim de que parem de nos incomodar a longo prazo. Já as memórias indesejadas de traumas são sintomas de uma mente que requer atenção a fim de que volte a funcionar de forma saudável. Segundo Schacter (2003, p.250):

"Os sete pecados não são meras irritações, que devem ser minimizadas ou evitadas. Eles também explicam como a memória recorre ao passado para informar o presente, preserva elementos de experiências atuais para futura referência e permite que voltemos ao passado quando desejamos. Os vícios da memória são também virtudes, elementos de uma ponte através do tempo, que permite que façamos uma ligação da mente com o mundo".

\section{Falsas memórias}

Nos últimos anos, questões críticas foram levantadas em relação à credibilidade da memória de adultos de suas experiências infantis. No cerne de tais alegações, encontra-se a idéia de que é possível implantar memórias de eventos que jamais ocorreram. Podemos supor que houve falsas memórias de incesto, e, certamente, algumas técnicas terapêuticas possuem maior probabilidade de promover falsas memórias do que outras. Além disso, existem indivíduos que são mais sugestionáveis do que outros podendo fazer com que acreditem em qualquer fato.

Lembranças falsas ocorrem quando uma pessoa acredita serem reais, mas

${ }^{55}$ SCHACTER, 2003. 
que por alguma razão são lembranças de eventos que nunca ocorreram. Participantes do estudo de testemunhas oculares que se recordaram de um galpão não existente estavam referindo-se a uma falsa lembrança, tal como o fez Piaget (1951) ao recordar-se da tentativa de seqüestro. Muitos pesquisadores de memória demonstram que é possível criar falsas lembranças da infância ${ }^{56}$.

O processo inicia-se quando absorvemos as coisas destinadas à memória. A maioria das percepções sensoriais não são registradas de forma consciente, e poucas delas permanecem retidas. A partir daí, a maioria delas apagam-se da mente em pouco tempo, e o restante é direcionado para a memória de longo prazo. Quando uma memória é lembrada, o processo de falsificação ganha novo impulso e, quando repassamos os fatos que ocorreram, acrescentamos um pouco de algo, perdemos outro e preenchemos com coisas que possam ter-se apagado. Assim, de forma inconsciente, podemos modificar gradualmente a lembrança com um pouco de imaginação. Segundo Carter (2003, p.336):

"O processo de codificar e representar o mundo que nos cerca e o mundo dentro de nós é automático. Aquilo com que, no final, acabamos ficando é um registro mental correspondente a qualquer evento, que não será completo nem será literal. Será fragmentário e interpretativo. Quando um evento é relembrado, o registro fragmentário é recuperado e nossos processos cognitivos operam no sentido de encontrar uma razão para ele. Nesse instante, é criado um outro registro de memória correspondente aos eventos no momento da rememoração, inclusive os resultados de quaisquer emoções que a acompanhem. Outras informações poderão ser incorporadas e, portanto, ao tentar se lembrar do evento original, você poderá se recordar do registro mais recente com os respectivos erros".

O comprovado fenômeno de recordar-se de algo que não foi vivenciado pode ocorrer sob duas formas: espontaneamente ou via sugestão externa. A primeira é o resultado de processos de distorção mnemônicos endógenos. Já as falsas memórias sugeridas surgem a partir de implantação exógena de falsa informação acidental ou deliberada ${ }^{57}$.

A Teoria do Traço Difuso é utilizada como modelo explicativo para os processos das falsificações de memória, admitindo que a memória é processada em dois sistemas independentes e em paralelo: literal (armazenamento específico dos detalhes dos fatos) e da essência (armazenamento do sentido e do significado).

${ }^{56}$ ABHOLD, 1992; LOFTUS, 1993; LOFTUS, 1997; LOFTUS E KETCHAM, 1991; WEEKS, LYNN, GREEN E BRENTAR, 1992, apud HUFFMAN, 2003.

57 STEIN, 1999. 
Tal pesquisa desenvolveu estudos na área de falsas memórias em população adulta brasileira, investigando, experimentalmente, o efeito do número de repetição de sugestões, bem como o efeito do tipo de repetição na formação das falsas memórias. Observou-se que as testemunhas repetiram exatamente a mesma informação, a memória para as frases verdadeiras melhorou. Já a repetição de informações diferentes pelas testemunhas, mas com o mesmo sentido, produziu aumento significativo das falsas memórias. Portanto, repetição de informações falsas provoca uma distorção da memória para o fato que realmente aconteceu ${ }^{58}$.

Em 1992, um grupo de adultos de meia-idade alarmados formou a primeira organização dedicada ao campo das distorções de memória: a Fundação Síndrome da Falsa Memória. Formada principalmente por pais que passavam por situações perturbadoras de conflito com suas filhas adultas, os primeiros membros da fundação contaram histórias que pareciam chocantes na época, mas que foram tornando-se familiares à medida que a década de 1990 avançava. Mulheres educadas e inteligentes de classe média começaram a fazer psicoterapia para superar a depressão e outros problemas relacionados. O tratamento acabava resultando no resgate de lembranças sobre abuso sexual na infância, em geral, atribuído aos pais e, algumas vezes, às mães. Os pais que organizaram a entidade, e muitos outros como eles, rejeitaram, enfurecidos, a legitimidade das lembranças das filhas. Os acusadores e seus simpatizantes criticavam, severamente, os pais por negar uma realidade que não podiam aceitar ${ }^{59}$.

Algumas lembranças resgatadas de abuso sexual infantil, esquecidas por muitos anos, podem parecer verdadeiras. A distorção da memória é decorrente de sugestões que fornecem informações muitas vezes errôneas da realidade.

Segundo Carter (2003), há situações em que uma pessoa pode não ser capaz de lembrar-se de traumas anteriores: 1) Quando uma memória não faz parte da crença habitual de alguém sobre ele mesmo, poderá não ser recuperada sem tentativa consciente; 2) Quando uma memória chegou inteira ou em parte à mente, mas foi rotulada ou interpretada como algo diferente; 3) Quando a memória não chegou à mente porque a pessoa não encontrou as dicas relevantes de recuperação durante muitos anos;4) Quando a memória de uma pessoa foi compartimentalizada de forma que determinados eventos só são rememorados em determinado estado da mente.

As distorções da memória também podem ocorrer em razão da confusão da fonte, que se dá quando a origem verdadeira da lembrança é esquecida ${ }^{60}$. A fonte é uma das partes da memória que são de fácil esquecimento.

${ }^{58}$ MORAIS, 1999.

59 SCHACTER, 2003.

${ }^{60}$ JOHNSON E COLS.,1993; LEICHTMAN \& CECI, 1995, apud HOCKENBURY, 2003. 
Segundo Bradon e cols. (1998), a memória é mais construtiva e reconstrutiva do que reprodutiva, é falível, alterada pela passagem do tempo e sujeita ao erro e à distorção. Considera que a memória individual autobiográfica não é confiável, e as pessoas, freqüentemente, são incapazes de relembrar partes consideráveis de suas experiências.

A fantasia e a imaginação de um fato ocorrido durante a infância que, provavelmente, não tenha ocorrido inflacionam a confiança de que tenha ocorrido. Muitas pessoas desacreditam que é possível fazer alguém se lembrar de algo que não ocorreu e passa a inventar detalhes a respeito de coisas que, de certa forma, teriam ocorrido, intensificando, ainda mais, a confiança na falsa memória. Tal inflação da imaginação pode ser criada pela hipnose, pela sugestão induzida por um terapeuta, pela interpretação de sonhos, pelos meios de comunicação ou pelo interrogatório na justiça.

Autores afirmam que instrução para imaginar um evento que não ocorreu pode levar as pessoas a criar realidade alternativa, mas instrução para imaginar um evento que ocorreu leva-as a recordar o evento passado ${ }^{61}$. As falsas memórias podem ser criadas também pelas exigências sociais com objetivo de recordar, pelo encorajamento, para imaginar eventos quando alguém está com dificuldade para lembrar-se e quando encorajado a não pensar se as recordações são reais ou não. Um estudo publicado por Loftus e cols. (1994) mostrou que uma em cada cinco mulheres, representando 19\% que relataram abuso sexual infantil, também relatou esquecimento completo do evento traumático por algum período de tempo e, posteriormente, recuperou a memória.

Outras pesquisas confirmam que é relativamente fácil estabelecer memórias referentes a um acontecimento que jamais ocorreu ao perguntar por ele. Segundo Hyman, Husband e Billings (1995), citado em Morris e Maisto (2003), quanto mais as pessoas são interrogadas a respeito, maiores as chances de que elas "se lembrem" dele. Às vezes, as memórias tornam-se reais para o participante do experimento. Em um deles, 25 por cento dos adultos "lembraram-se" de acontecimentos fictícios na terceira vez em que foram entrevistados a respeito. Um dos acontecimentos fictícios consistia em derrubar uma poncheira sobre os pais da noiva em uma festa de casamento. Na primeira entrevista, a pessoa "lembrou-se" de que a festa acontecera ao ar livre e que havia derrubado a poncheira enquanto corria pra lá e pra cá. Alguns, até mesmo, "lembraram-se" de detalhes, como a aparência das pessoas e o que elas estavam vestindo. Não obstante, os pesquisadores registraram o fato de que esses acontecimentos jamais ocorreram. Outra pesquisa demonstra que as pessoas podem até ser convencidas de que se lembram de fatos ocorridos durante sua infância ${ }^{62}$.

${ }^{61}$ MEARES, 1961, apudFERREIRA, 2003.

${ }^{62}$ SPANOS, 1996; SPANOS, BURGESS, BURGESS, SAMUELSeBLOIS, 1997, apudMORRISeMAISTO, 2004. 
A suposição dessa e de outras pesquisas semelhantes é a de que é plenamente possível que as pessoas "se lembrem" de experiências que nunca aconteceram. Segundo Imrie (1999), citado em Morris e Maisto (2004), alguns que "recuperaram" memórias referentes a abusos, mais tarde, perceberam que tais acontecimentos jamais ocorreram. Algumas até processaram os terapeutas que, segundo elas, recuperaram tais memórias. Um exemplo disso está no caso da mulher que venceu um processo no valor de US\$ $850 \mathrm{mil}$.

\section{Método}

\section{Participantes}

A amostra foi constituída de 30 participantes, funcionários de uma empresa de transporte coletivo do Distrito Federal, 15 do sexo masculino e 15 do sexo feminino, com idades entre 20 e 32 anos (média de 26,07 e desvio-padrão de 3,45).

\section{Estímulos}

Foram apresentados vinte slides na tela de um computador, contendo imagens faciais de tamanho $15 \times 12$ centímetros de homens e mulheres com diferentes traços. A apresentação de cada slide era de dez segundos, passando, automaticamente, para o slide seguinte após este período. O experimento todo durava, aproximadamente, 3 minutos.

\section{Procedimento}

A coleta de dados foi realizada individualmente. O participante ficava posicionado em frente ao computador. Em seguida, o experimentador apresentava os estímulos de 20 imagens faciais de diferentes traços, informando ao examinado que se tratava de simples teste de memória e que teria dez segundos para visualizar cada uma delas. Após a visualização e a memorização das imagens, o experimentador apresentava outra imagem sobre a qual era perguntado se tal imagem esteve presente entre as outras. Se a resposta fosse positiva, o experimentador dizia frases para convencê-lo de que não estava presente, dizendo: "Na verdade, a foto não estava presente". Caso a resposta fosse negativa, tentaria convencer o sujeito de que a imagem estava presente em meio às demais, por meio da frase "Bem, na verdade, a foto estava presente". O registro era feito após a resposta do participante do qual constava se houve ou não a criação de falsas memórias. 


\section{Resultados}

Dos trinta respondentes, 56,7\% apresentaram falsa memória, enquanto 43,3 $\%$ não apresentaram. Nenhuma correlação foi encontrada em relação à idade e ao sexo dos participantes, porém foi encontrada correlação significativa da falsa memória e do nível de escolaridade (Pearson $=-0,656 ; \mathrm{P}<0,01$ ), como podemos observar na Figura 1. O nível de escolaridade dos participantes era de 3,3\% (primeiro grau completo), $20 \%$ (segundo grau incompleto), $40 \%$ (segundo grau completo), 23,3\% (terceiro grau incompleto) e 13,3\% (terceiro grau completo).

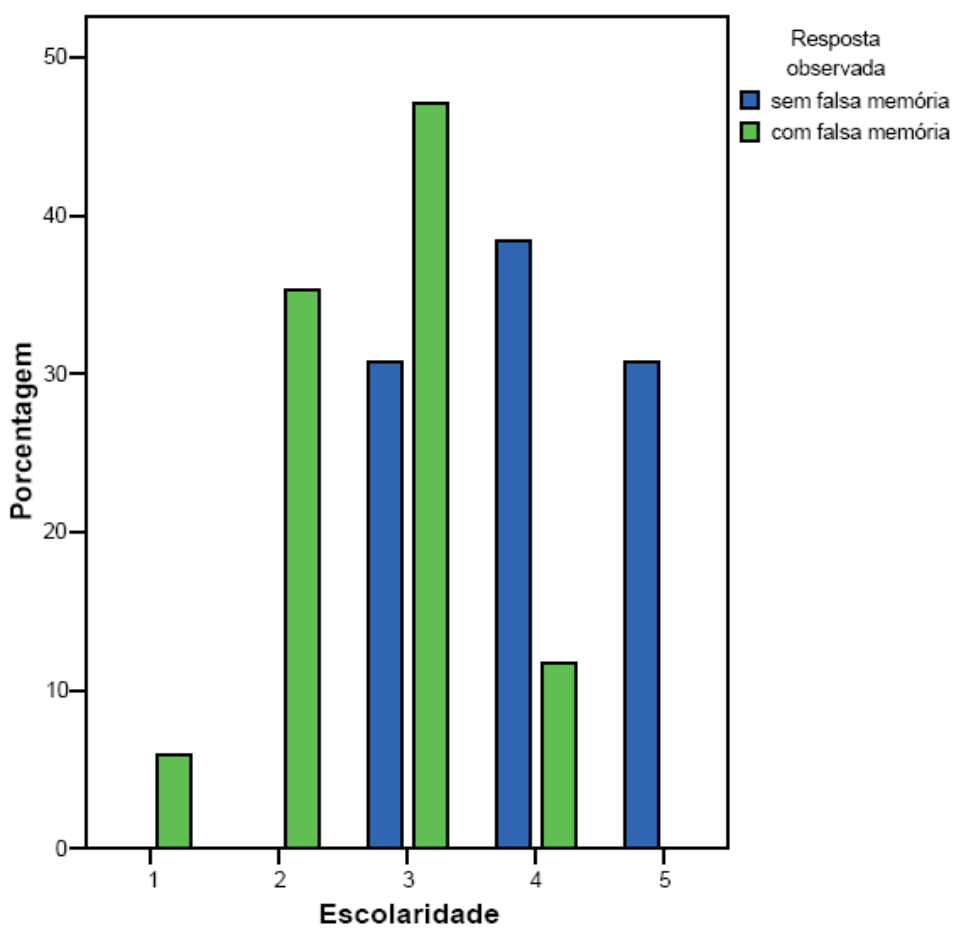

Figura 1 - Pode-se observar que os participantes de baixa escolaridade $\left(1,2\right.$ e 3 - $1^{\circ}$. grau completo, $2^{\circ}$. grau incompleto e $2^{\circ}$. grau completo, respectivamente) tiveram mais falsas memórias do que os de nível superior incompleto e completo (4 e 5). 


\section{Discussão}

Por meio dos resultados obtidos, percebe-se que não há diferença entre a criação de falsa memória em homens e mulheres. O nível de escolaridade foi fundamental na compreensão do fenômeno de falsas memórias. Os sujeitos com escolaridade mais baixa apresentaram mais falsas memórias do que os sujeitos com escolaridade mais elevada. Isto demonstra que o nível educacional e cultural do indivíduo pode influenciar no modo pelo qual as pessoas respondem a sugestões fornecidas pelo computador e pelo experimentador, criando memórias falsas.

Diante das perguntas realizadas a respeito das imagens faciais, observouse que dois sujeitos, ambos de nível médio incompleto, permaneceram, aproximadamente, 03 (três) minutos em reflexão antes de responder. De acordo com Miltner (2002), o método de treino da memória, com a ajuda de imagens, é denominado visualização, isto é, imaginar um objeto figurativamente. Ao serem questionados a respeito do tempo de reflexão, os sujeitos alegaram que precisavam de um tempo para "pensar" se, realmente, viram as imagens ou não, tentando relembrar as imagens anteriores.

A pesquisa não é conclusiva, pois surge uma variável que necessita ser melhor descrita e ter os seus efeitos conhecidos, como, por exemplo, o fator social implicado em tornar possível a construção de memórias falsas. Parece que a sugestionabilidade é maior nas pessoas de baixa escolaridade, as quais estariam mais predispostas à formação de falsas memórias para não contradizerem as informações contidas no computador ou num experimentador, porém os mais instruídos questionavam as informações apresentadas.

\section{Conclusão}

De acordo com Miltner (2002), só conseguimos lembrar-nos bem das coisas que nos interessam e prestamos a elas a atenção necessária e, assim, ficam gravadas por muito tempo. Os problemas de memória devem-se, muitas vezes, à falta de atenção e de concentração. Portanto, as informações captadas pelos sujeitos de modo fragmentado tornaram-se difíceis de ser recordadas posteriormente, ratificando os dados da pesquisa.

Não adquirimos nossa capacidade de memória do berço. Embora a natureza nos tenha dotado de sistema de memória inesgotável, a informação que armazenamos e aquela que se mantém acessível e utilizável dependem do modo como os

dados foram guardados e agrupados. É por isso que as coisas agradáveis são 
facilmente recordadas, e aquilo que é desinteressante, que tivemos de aprender sem entusiasmo, só relembramos com dificuldade. Segundo Miltner (2002), quanto mais positiva for a nossa idéia sobre a matéria a ser aprendida, mais facilmente conseguiremos memorizá-la. Uma regra importante é estar motivado e estabelecer objetivos positivos.

\section{Referências}

ATKINSON, R. L.et al. Introdução à psicologia de Hilgard. Trad. BUENO, D. 13. ed. Porto Alegre: Artmed, 2002.

BALLONE, G. J. “Atenção e Memória”. In: Psiq Web Psiquiatria Geral. Disponível: http:// www.psiqweb.med.br/cursos/memoria.html. Acessado em 12 out. 2004.

BUSER, P. Cérebro de si cérebro do outro. Neurologia, consciência e inconsciente. Trad. RABAÇA, A. Lisboa: Instituto Piaget, 1998.

CARTER, R. O livro de ouro da mente. Trad. ASSIS, V. P. Rio de Janeiro: Ediouro, 2003.

COFER, C. N. Memória e esquecimento. Trad. CRAVEIRO, J.Brasília: Brasiliense, 1977.

DAVIDOFF, L. L. Introdução à psicologia. Trad. PEREZ. 3. ed. São Paulo: Makron Books, 2001.

Doença de Alzheimer. Disponível: http://www.network.sistemas.com.br/neuropsicologia/ neuro_fotos.htm. Acessado em 15 set. 2004.

FERREIRA, M. V. C. Hipnose na prática clínica. São Paulo: Atheneu, 2003.

HITIER, R.; PETIT, F.; PRÉAT, T. Memórias de uma mosca.In: Viver Mente\&Cérebro, São Paulo: Duetto, n. 140, p. 74-81, set. 2004.

HOCKENBURY, D. H.; HOCKENBURY, S. E. Trad. KEELING, J. H.; KEELING, E. L. 2. ed. Descobrindo a psicologia. São Paulo: Manole, 2003.

HUFFMAN, K.; VERNOY, M.; VERNOY, J. Trad. YAMAMOTO, M. A. Psicologia. São Paulo: Atlas, 2003.

IZQUIERDO, I. et al. Mecanismos da memória. In: Scientific American, São Paulo: Duetto, n. 17, p. 98-104, out. 2003.

KANDEL, E. R.; SCHWARTZ, J. H.; JESSELL, T. M. Princípios da neurociência. Trad. PEREIRA, A. C. G. 6. ed. São Paulo: Manole, 2003.

LEDOUX, J. O cérebro emocional: os misteriosos alicerces da vida emocional. Trad. SANTOS, T. B. 7. ed. Rio de Janeiro: Objetiva, 2001.

LOFTUS, E. F. Criando falsas memórias. Artigos/ensaios psicologia. Disponível: http:// www.ateus.net/artigos/psicologia/criando_falsas_memorias.html. Acessado em 22 jul. 2004.

Memória: o que é e como melhorá-la. Por Dra. Silvia Helena Cardoso. Disponível: http:// www.cerebromente.org.br/n01/memo/memoria.htm. Acessado em 24 set. 2004. 
MILNER, P. M. Psicologia fisiológica. Trad. DANTAS, H. L. São Paulo: Cultrix, 1970.

MILTNER, F. et al. . Domine os poderes de sua mente. Pense melhor, viva melhor: como desenvolver sua inteligência de forma fácil e divertida. Trad. PEREIRA, S. G. Rio de Janeiro: Reader's Digest, 2002.

MORRIS, C. G.; MAISTO, A. A. Introdução à psicologia. Trad. LIMA, L; BAPTISTA, M. S. D. 6. ed. São Paulo: Prentice Hall, 2004.

SACKS, O. W. O homem que confundiu sua mulher com um chapéu. Trad. MOTTA, L. T.

São Paulo: Companhia das Letras, 2002.

SCHACTER, D. L. Os sete pecados da memória: como a mente esquece e lembra. Trad. GUNN, S. A. Rio de Janeiro: Rocco, 2003.

SQUIRE, L. R.; KANDEL, E. R. Memória. Da mente às moléculas. Trad. DALMAZ, C. Porto Alegre: Artmed, 2003.

STEIN, L. M. et al. Falsas memórias e relatos de testemunhas. XXX Reunião Anual de Psicologia. Rio Grande do Sul: Sociedade Brasileira de Psicologia, 1999. 


Para publicar na revista Universitas - Ciências da Saú-
de, encaminhe seu artigo original para:
Campus do Centro Universitário de Brasília UniCEUB,
SEPN 707/907, Bloco 9, Faculdade de Ciências da Saúde,
CEP 70.790-075, Brasília-DF.
e-mail: universitas.saude @ uniceub.br
Aos cuidados do Editor da revista.
Observe as Normas de Publicação.

